\title{
Comparing of Physiologic Delivery and Traditional Vaginal Delivery in Pregnant Women Who Come to Kosar Hospital
}

\author{
${ }^{1}$ Fatemeh Lalooha, ${ }^{1}$ Faride Movahed, ${ }^{1}$ Talaat Dabaghi Ghaleh, ${ }^{2}$ Leila Alijani and ${ }^{3}$ Omid Mashrabi \\ ${ }^{1}$ Department of Obstetrics and Gynecology, \\ ${ }^{2}$ Department of Gynecology, Faculty of Medicine, \\ Ghazvin University of Medical Sciences, Ghazvin, Iran \\ ${ }^{3}$ Women's Reproductive Health Research Center, Department of Obstetrics and Gynecology, \\ Faculty of Medicine, Tabriz University of Medical Sciences, Tabriz, Iran
}

\begin{abstract}
Abstarct: In traditional vaginal delivery used any intervention such as: IV line, prescription of oxytocin and episiotomy but in physiologic delivery did not do any intervention and exit of placenta was spontaneously and patient position in favorable situation. Comparing laceration and hemoglobin decrease in physiologic delivery and traditional vaginal delivery. Recent study are analytical epidemiologic study, case control that doing in 500 pregnant women who come to Kosar hospital with labor pain that randomly divided in two groups of traditional vaginal and physiologic delivery ( 250 cases in each group) and progress of delivery controlled then information an questionnaires completed. In recent study, in traditional vaginal delivery, $73.2 \%$ cases was used episiotomy. In physiologic group in $66.8 \%$ of cases there was not any laceration and $29.6 \%$ of cases grade I, $3.6 \%$ of cases laceration grade II. In traditional vaginal delivery in $26.8 \%$ of case there was not any episiotomy. That there was not laceration in $53.7 \%, 41.8 \%$ laceration grade I and $4.3 \%$ laceration grade II. The mean of $\mathrm{Hb}$ after $6 \mathrm{~h}$ of delivery in physiologic delivery was statically higher than traditional vaginal delivery $(\mathrm{p}<0.001)$. The findings show that the risk of laceration and decrease of $\mathrm{Hb}$ in physiologic delivery is less than traditional vaginal delivery. So, researchers can use physiologic delivery as routine.
\end{abstract}

Key words: Episiotomy, tearing, vaginal delivery, $\mathrm{Hb}$ decrease, rise of laceration, Iran

\section{INTRODUCTION}

Labor is a physiological process that God has provided its fulfillment means and circumstances in humans just like other mammals. Surveys and studies have shown that about $85 \%$ of normal deliveries do not require medical intervention. Childbirth is a process that begins with uterine contractions and ends with the placenta coming out. This process is called labor (Cunningham et al., 2009).

In 2003 in Parkland hospital, only 2139 (53\%) of pregnant women with a singleton fetus with cephalic view had spontaneous delivery. The rest had ineffective and needed reinforcement (Cunningham et al., 2009). Various interventions may be made by delivery agents during vaginal delivery including: Enemas, IV line, vaginal examination, use of oxytocin and putting the mother in the lithotomy position. One of the most common interventions routinely used by most of physicians is episiotomy which is a surgical cut in the perinea to widen the vaginal opening that can be midline or mediolateral and local anesthesia is required for this operation. It is suggested that the episiotomy blade decreases perineal trauma and further pelvic floor defects will not occur. Blood loss during labor will be also reduced and birth trauma will be prevented. Some studies have shown that there is no relationship between the disability and application of episiotomy (Signorello et al., 2000). Out of benefits of episiotomy is that the mother can walk easier after delivery, sit more comfortably and take care of your baby better (Hartmann et al., 2005). In case of not using episiotomy, mother may suffer rupture which is mostly of first grade. First grade laceration does not need to be repaired and it is only recommended to keep the site clean. Also in second grade, laceration repair is not typically needed, unless there is a bleeding vessel (Albers et al., 2006). In physiological delivery, no intervention such as IV line, administration of oxytocin etc. is done. Episiotomy is not used and the patient performs the labor in any position she may prefer and the labor is not necessary to be done in lithotomic position and the exit of will be spontaneous. Regarding these, in the recent study, the

Corresponding Author: Faride Movahed, No. 20, Shakeri Alley, Jahad Ave., Imam Street, Ajabshir, East Azarbayjan Province, Iran 
typical vaginal delivery and physiological delivery were studies and the main aim was to investigate the rate of laceration and bleeding in both groups.

\section{MATERIALS AND MATHODS}

In this epidemiological analytic study of case-control kind conducted in 2008, pregnant women with labor pains admitted to Kosar hospital were studied. Sampling was done by completely random sampling method. After pregnant women with labor pains referring to the hospital, patients got initial examination and were admitted and their histories were received by assistants and obstetricians. Then, cases of the study group were selected according to inclusion and exclusion criteria and set to two groups of normal and physiological delivery using colored cards.

Labor course was monitored by obstetricians and assistants and on occurrence of any exclusion factor during this period, the cases were excluded from the study. It should be noted that in Kosar hospital, the initial hemoglobin was routinely checked at $6 \mathrm{~h}$ after delivery. According to investigation, sample volume in either group was calculated:

$$
250, \alpha / 2=0.025, \beta=0.2, \mathrm{~d}=0.5, \delta=2
$$

Inclusion criteria were: pregnant women with active phase of labor (dilatation $3 \mathrm{~cm}$ ) or efficient labor pain but less dilatation, cephalic demonstration, singleton, no need to reinforcement by oxytocin, term pregnancy ( 37 weeks or more). Exclusion criteria of the study were the 1st pregnancy with age $>35$ years long ruptured Amniotic sac $(>12 \mathrm{~h}$ ) without labor pain, mother with systemic diseases, abnormal demonstrations of infant, history of previous cesarean or previous cut on the uterus, suspected macrocosmic infant or the CPD mother, preeclampsia, placental abruption and placenta previa, etc., multipara, non-Iranian race (Afghani). After collection of data, findings were presented in the form of statistical tables, charts and numerical indices. For data analysis, t-test, Chi-square $\left(\chi^{2}\right)$ and Fisher exact test were used. Significance level was considered as $5 \%$.

\section{RESULTS}

This study was conducted on 500 pregnant women with labor pains referred to Kosar hospital that 250 of them were put in the typical vaginal delivery group and 250 in the physiological labor group. Distribution of age, gravidity, number of previous term deliveries, history of previous preterm delivery, miscarriage, dilatation at
Table 1: Age distribution of patients in two groups

\begin{tabular}{lcrr}
\hline Age groups (years) & Physiologic labor (\%) & Common labor (\%) & Total (\%) \\
\hline$<20$ & $8(3.2)$ & $16(6.4)$ & $24(4.8)$ \\
$20-34$ & $213(85.2)$ & $215(86.0)$ & $428(85.6)$ \\
$>34$ & $29(11.6)$ & $19(7.6)$ & $48(9.6)$ \\
Total & $250(100.0)$ & $250(100.0)$ & $500(100.0)$ \\
\hline
\end{tabular}

Table 2: Cervical dilatation score between two groups of patients Cervical dilatation score Physiologic labor (\%) Common labor (\%) Total (\%)

\begin{tabular}{lrrr}
\hline 2 & $53(21.2)$ & $80(32.0)$ & $133(26.6)$ \\
3 & $86(34.4)$ & $76(30.4)$ & $162(32.4)$ \\
4 & $45(18.0)$ & $40(16.0)$ & $85(17.0)$ \\
5 & $23(9.2)$ & $18(7.2)$ & $41(8.2)$ \\
6 & $9(3.6)$ & $9(3.6)$ & $18(3.6)$ \\
7 & $8(3.2)$ & $4(1.6)$ & $12(2.4)$ \\
8 & $10(4.0)$ & $10(4.0)$ & $20(4.0)$ \\
9 & $5(2.0)$ & $4(1.6)$ & $9(1.8)$ \\
10 & $11(4.4)$ & $9(3.6)$ & $20(4.0)$ \\
Total & $250(100.0)$ & $250(100.0)$ & $500(100.0)$ \\
\hline
\end{tabular}

admission and infant weight were identical in both groups and there was no significant difference between the two groups in terms of the mentioned factors. Mean age was $27.72 \pm 5.32$ in the physiological delivery group and $26.92 \pm 5.022$ in the typical vaginal delivery group. The largest age range was 20-34 years (Table 1). There was no significant difference between age groups in terms of age groups ( $\mathrm{p}=0.93$ ). Mean gravidity was $2.66 \pm 1.06$ in the physiological delivery group and $2.49 \pm 0.98$ in the typical vaginal delivery group that there was no statistically significant difference between the two groups $(p=0.074)$. About $3 \mathrm{~cm}$ dilatation had the largest population in the group. Mean dilatation at the time of admission was $4.2 \pm 2.111$ in the physiological labor group and $3.7 \pm 2.052$ in the typical vaginal delivery group that there was no statistically significant difference between the two groups $(\mathrm{p}=0.94)$ (Table 2). Mean birth weight of infants was $3183.20 \pm 386.819$ in the physiological labor group and $324.96 \pm 456.271$ in the typical vaginal delivery group that there was no statistically significant difference between the two groups $(p=0.78)$. In the physiological delivery group that episiotomy was not used in any case, 167 cases $(66.8 \%$ ) had no laceration. About $29.6 \%$ had 1 st grade laceration and $3.6 \%$ had 2 nd grade laceration and there was no $3 \mathrm{rd}$ or 4 th grade laceration.

In the typical vaginal delivery group, 183 cases (73.2\%) had episiotomy and only $67(26.8 \%)$ did not have episiotomy that $36(53.7 \%)$ out of them had no laceration, $41.8 \%$ had 1 st grade laceration and $4.5 \%$ had 2 nd grade laceration. There was no $3 \mathrm{rd}$ and 4 th grade laceration (Table 3 and 4). Mean hemoglobin level at the time of admission was $12.556 \pm 1.1881$ in physiological labor and $12.682 \pm 1.0568$ in the typical vaginal delivery group that there was no significant difference between the two groups $(p=0.212)$. Mean hemoglobin level at $6 \mathrm{~h}$ after 
Table 3: Episiotomy frequency between two groups

\begin{tabular}{lccr}
\hline Episiotomy & Physiologic labor (\%) & Common labor (\%) & Total (\%) \\
\hline Yes & $0(0)$ & $183(73.2)$ & $183(36.6)$ \\
No & $250(100)$ & $67(26.8)$ & $317(63.4)$ \\
Total & $250(100)$ & $250(100.0)$ & $500(100.0)$ \\
\hline
\end{tabular}

Table 4: Perineal laceration grades between two groups

Perineal laceration Physiologic labor (\%) Common labor (\%) Total (\%)

\begin{tabular}{llll}
\hline None & $167(66.8)$ & $219(87.6)$ & $386(77.2)$
\end{tabular}

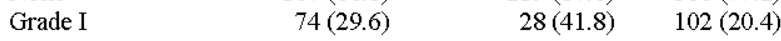

Grade II $\quad 9(3.6) \quad 3(4.5) \quad 12(2.4)$

$\begin{array}{llll}\text { Grade III and IV } & 0(0.0) & 0(0.0) & 0(0.0)\end{array}$

\begin{tabular}{llll} 
Total & $250(100.0)$ & $250(100.0)$ & $500(100.0)$ \\
\hline
\end{tabular}

delivery was $12.479 \pm 1.158$ in physiological labor group and $11.618 \pm 0.223$ in the typical vaginal delivery group that there was a statistically significant difference between the two groups $(\mathrm{p}=0.000)$.

\section{DISCUSSION}

One of the most common interventions during vaginal delivery is episiotomy because many physicians believe it will reduce perineal trauma and rupture will not occur (Signorello et al., 2000) but some studies showed that perineal trauma will not increase without episiotomy and blood loss will be even less (Albers et al., 2006). In this study, episiotomy was used in $73.2 \%$ of the typical vaginal delivery group while in a study by Weber and Meyn (2002) it had been shown that in 1979, episiotomy was used for $65 \%$ of women and this amount has decreased to $39 \%$ in 1997 . In other studies, it is also mentioned that the routine use of episiotomy has dropped (Albers et al., 2006). This could be because of different perineal conditions due to differences of race or prepare for birth mothers. However, physician's tendency to use episiotomy is also very important.

In the physiological delivery group that had no episiotomy, $66.8 \%$ had no laceration, $9.6 \%$ had first grade laceration and $3.6 \%$ had second grade laceration. In the typical vaginal delivery group, $73.2 \%$ had episiotomy and $26.8 \%$ were without episiotomy. Out of the non-episiotomy cases, $53.7 \%$ had no laceration, $41.8 \%$ had first grade laceration and $4.5 \%$ had second grade laceration. This means that despite no use of episiotomy in the physiological labor group, laceration rate was lower. This has also been confirmed in the study by Albers et al. (2006). The reason could be that any manipulation of the perineum during delivery may increase labor complications because perineum is very sensitive (susceptible). Hemoglobin level drop in physiological labor group was less than that in the typical vaginal delivery group. In a study by Albert et al. (2006), blood loss was less in the group with spontaneous laceration whereas in the study by Thacker and Banta (1983), episiotomy group had less blood loss. And in the study by Thilaganathan et al. (1993), blood loss was less in the group with spontaneous laceration (Thacker and Banta, 1983), it is shown that with physiological management of placenta exit where the umbilical cord is not clamped and the placenta exits due to the efforts of the mother much more blood will be lost. The reason could be that the laceration in physiological delivery are often low-grade laceration and do not even need to repair. However, bleeding is much more in episiotomy and according to a general rule, any manipulation while the placenta exit will cause further complications.

\section{CONCLUSION}

The results by this study generally show that the rupture rate in the physiological delivery (despite not using episiotomy) is less than that in the typical vaginal delivery and hemoglobin level drop is also lower. Therefore, it can be described that physiological delivery (without intervention) should be included in the state plans as an approach to increase the rate of vaginal delivery and decrease cesarean section rates and its complications.

\section{REFERENCES}

Albers, L.L., K.D. Sedler, E.J. Bedrick, D. Teaf and P. Peralta, 2006. Factors related to genital tract trauma in normal spontaneous vaginal births. Birth, 33: $94-100$.

Cunningham, F.G., J.W. Williams, K.J. Leveno, S. Bloom, J.C. Hauth and D.J. Rouse, 2009. Williams Obstetrics. 23rd Edn., McGraw-Hill Medical, New York, USA., ISBN-13: 9780071497015, Pages: 1385.

Hartmann, K., M. Viswanathan, R. Palmieri, G. Gartlehner, J. Thorp Jr. and K.N. Lohr, 2005. Outcomes of routine episiotomy: A systematic review. J. Am. Med. Assoc., 293: 2141-2148.

Signorello, L.B., B.L. Harlow, A.K. Chekos and J.T. Repke, 2000. Midline episiotomy and anal incontinence: retrospective cohort study. Br. Med. J., 320: 86-90.

Thacker, S.B. and H.D. Banta, 1983. Benefits and risks of episiotomy: An interpretative review of the English language literature, 1860-1980. Obstetrics Gynecol. Surv., 38: 322-338.

Thilaganathan, B., A. Cutner, J. Latimer and R. Beard, 1993. Management of the third stage of labour in women at low risk of postpartum haemorrhage. Eur. J. Obstetrics Gynecol. Reprod. Biol., 48: 19-22.

Weber, A.M. and L. Meyn, 2002. Episiotomy use in the United States, 1979-1997. Obstetrics Gynecol., 100: $1177-1182$. 